PAPER • OPEN ACCESS

Assessing edge cracking resistance in AHSS automotive parts by the Essential Work of Fracture methodology

To cite this article: D Frómeta et al 2017 J. Phys.: Conf. Ser. 896012102

View the article online for updates and enhancements.
Related content

- A new specimen for out-of-plane shear
$\frac{\text { strength of advanced high strength steel }}{\text { Bheets }}$
B Gu, J He, S H Li et al.
- Fracture Toughness of YBaCuO Prepared
$\frac{\text { by MPMG Process }}{\text { Hiroyuki Fujimoto, Masato Murakami, }}$
Terutsugu Oyama et al.
- Development of a Hybrid Deep Drawing
Process to Reduce Springback of AHSS
Vladimir Boskovic, Christoph Sommitsch
and Mustafa Kicin

Recent citations

- A simplified stress-based forming limit
$\frac{\text { criterion for advanced high strength steel }}{\text { (AHSS) }}$
B M Hance and L Huang

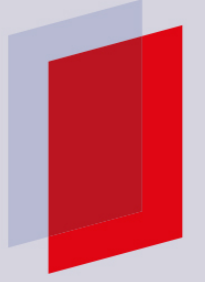

\section{IOP ebooks}

Bringing you innovative digital publishing with leading voices

to create your essential collection of books in STEM research.

Start exploring the collection - download the first chapter of every title for free. 


\title{
Assessing edge cracking resistance in AHSS automotive parts by the Essential Work of Fracture methodology
}

\author{
D Frómeta ${ }^{1}$, M Tedesco ${ }^{2}$, J Calvo ${ }^{3}$, A Lara ${ }^{1}$, S Molas ${ }^{1}$ and D Casellas ${ }^{1,4}$ \\ ${ }^{1}$ Fundació CTM Centre Tecnològic, Plaça de la Ciència 2, 08243 Manresa, Spain \\ ${ }^{2}$ Centro Ricerche Fiat, Corso Settembrini 40, 10135 Turin, Italy \\ ${ }^{3}$ Universitat Politècnica de Catalunya, Eduard Maristany 10-14, 08019 Barcelona, Spain \\ ${ }^{4}$ Luleå University of Technology, 97187 Luleå, Sweden \\ E-mail: david.frometa@ctm.com.es
}

\begin{abstract}
Lightweight designs and demanding safety requirements in automotive industry are increasingly promoting the use of Advanced High Strength Steel (AHSS) sheets. Such steels present higher strength (above $800 \mathrm{MPa}$ ) but lower ductility than conventional steels. Their great properties allow the reduction of the thickness of automobile structural components without compromising the safety, but also introduce new challenges to parts manufacturers. The fabrication of most cold formed components starts from shear cut blanks and, due to the lower ductility of AHSS, edge cracking problems can appear during forming operations, forcing the stop of the production and slowing down the industrial process.

Forming Limit Diagrams (FLD) and FEM simulations are very useful tools to predict fracture problems in zones with high localized strain, but they are not able to predict edge cracking. It has been observed that the fracture toughness, measured through the Essential Work of Fracture (EWF) methodology, is a good indicator of the stretch flangeability in AHSS and can help to foresee this type of fractures.

In this work, a serial production automotive component has been studied. The component showed cracks in some flanged edges when using a dual phase steel. It is shown that the conventional approach to explain formability, based on tensile tests and FLD, fails in the prediction of edge cracking. A new approach, based on fracture mechanics, help to solve the problem by selecting steel grades with higher fracture toughness, measured by means of EWF. Results confirmed that fracture toughness, in terms of EWF, can be readily used as a material parameter to rationalize cracking related problems and select AHSS with improved edge cracking resistance.
\end{abstract}

\section{Introduction}

AHSS present excellent mechanical properties that poses them as a great option for safety components, structural parts of the car body and chassis, reducing the total vehicle mass and enhancing crashworthiness. Their use in the automotive industry has been strongly extended in the last two decades in order to fulfill the more and more demanding safety and fuel consumption legislations [1]. The use of this kind of steels has introduced new issues that are not completely solved. One of them is the edge cracking in cold formed sheet components. AHSS present high strength (600-1200 MPa) but limited ductility, compared to conventional mild steels, which makes them more sensitive to premature cracking during cold forming operations, especially in trimmed, sheared or punched areas, where the material is 
damaged and defects, such as micro cracks can be present [2-4]. These defects can trigger the crack propagation through the sheet thickness during the subsequent cold forming processes and lead to the fracture of the component [4]. Figure 1 shows some examples of cracks in cold formed components.
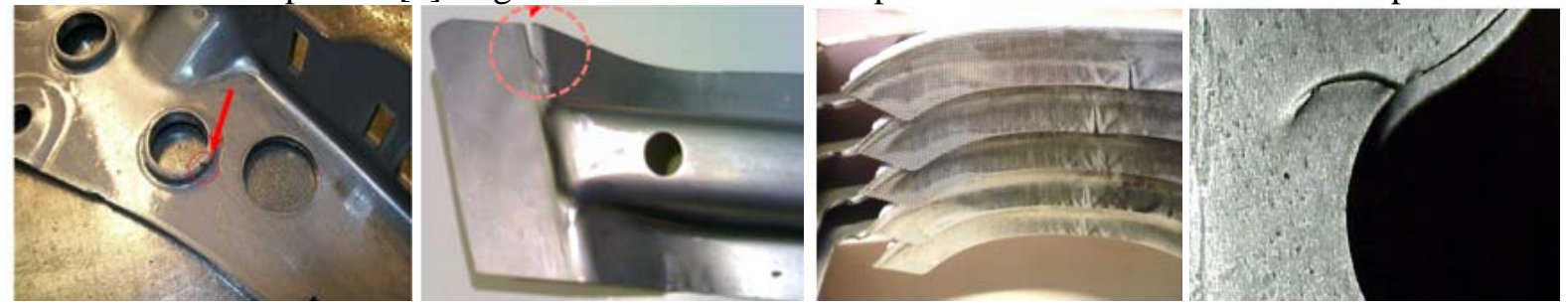

Figure 1. Examples of edge cracking in cold formed components

Intensive research has been made on this issue and great efforts have been put on the development of failure criteria to predict this type of fractures. It has been shown that conventional approaches, such as FLD or tensile tests are not valid to predict them [5-6]. Hence, additional tests are required to quantify the edge cracking sensitivity of AHSS. In this regard, stretch flangeability, measured by the Hole Expansion Test (HET), has shown to be suitable to foresee edge cracking related problems and has become an important parameter to consider in AHSS sheets formability [7].

Previous works showed that stretch flangeability of AHSS is governed by the crack propagation resistance of the material [8-11]. Casellas et al. analysed the correlation between stretch flangeability and fracture toughness (in terms of Essential Work of Fracture, EWF) on several AHSS grades with different microstructure and a quite good correlation between the two parameters was found [10]. AHSS showing higher EWF values presented higher Hole Expansion Ratio (HER), i.e. the tougher the material the greater the stretch flangeability. Other authors found the same trend between HER and $J_{c}$ values [11]. Thus, fracture toughness, could be used to rationalize edge cracking and rank the stretch flangeability of AHSS.

Nevertheless, within the frame of Elastic Plastic Fracture Mechanics (EPFM), no standard methods are available to readily measure the fracture toughness of thin steel sheets presenting plane stress conditions. Conventional EPFM methodologies (J-Integral, CTOD, J-R curves, etc.) are standardized for plane strain conditions and their implementation requires exhaustive sample preparation, time consuming tests with constant monitoring and rigorous data treatment [12].

The EWF methodology was developed by Cotterell and Reddel [13] in the 80s as an alternative to measure the fracture toughness of thin plates under plane stress and was applied successfully to polymers [14-16] and ductile metals [17-20]. More recently, the methodology has been applied to AHSS sheets and has shown to be appropriate to evaluate the fracture toughness [10, 21-23]. The main advantage of this methodology is the relative easiness of the procedure compared to the other methods.

This work aims to provide a reliable tool, based on fracture mechanics, able to discern the edge cracking sensitivity of AHSS sheets and avoid unexpected fractures in industrial cold formed components. For this purpose, a serial production automotive part has been studied. The component presented multiple cracks in stretched flanges when manufactured with a dual phase (DP) steel (figure 2). The problem was solved replacing the DP steel grade by a complex phase (CP) steel with the same maximum strength and thickness. Different mechanical tests, including an EPFM-based one, were used to assess the edge cracking resistance of AHSS. 


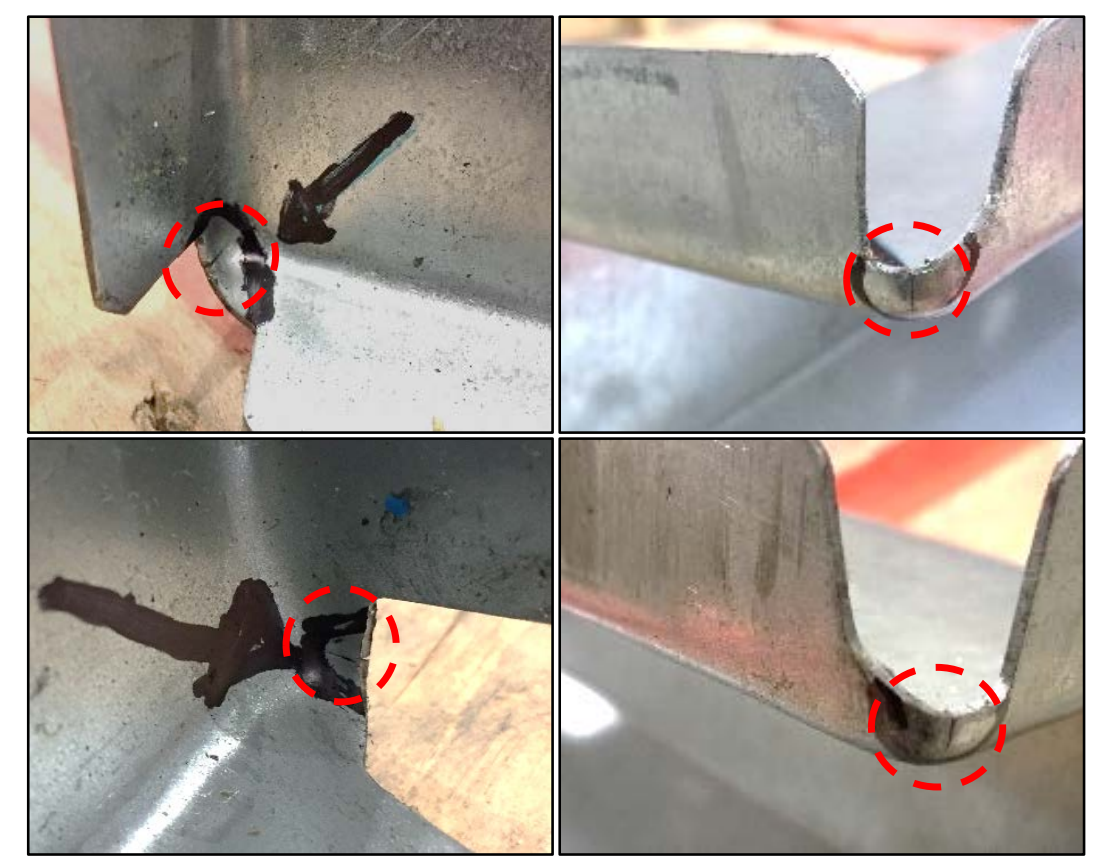

Figure 2. Edge cracks observed in the component manufactured with DP steel grade.

\section{Materials}

The materials investigated were two $1^{\text {st }}$ generation AHSS grades of 1000 MPa UTS, commonly used for lightweight automotive components: a DP steel and a CP steel. Both steel grades are presented in form of sheets of $1.2 \mathrm{~mm}$ thickness. The chemical composition of the steels is shown in table 1. A basic microstructural characterization was performed by means of Scanning Electron Microscopy (SEM). The results are shown in figure 3. DP1000 presents a matrix consisting on a mixture of ferrite and martensite whereas CP1000 exhibits a more homogeneous microstructure, consisting on a bainite/tempered martensite matrix.

Table 1. Chemical composition of the studied steels (in wt\%)

\begin{tabular}{ccccccc}
\hline Steel grade & C & Si & Mn & Cr & B & Al \\
\hline CP1000 & $\sim 0.1$ & $<0.5$ & $1.8-2.2$ & $<0.7$ & $<0.003$ & - \\
\hline DP1000 & $\sim 0.15$ & & &
\end{tabular}
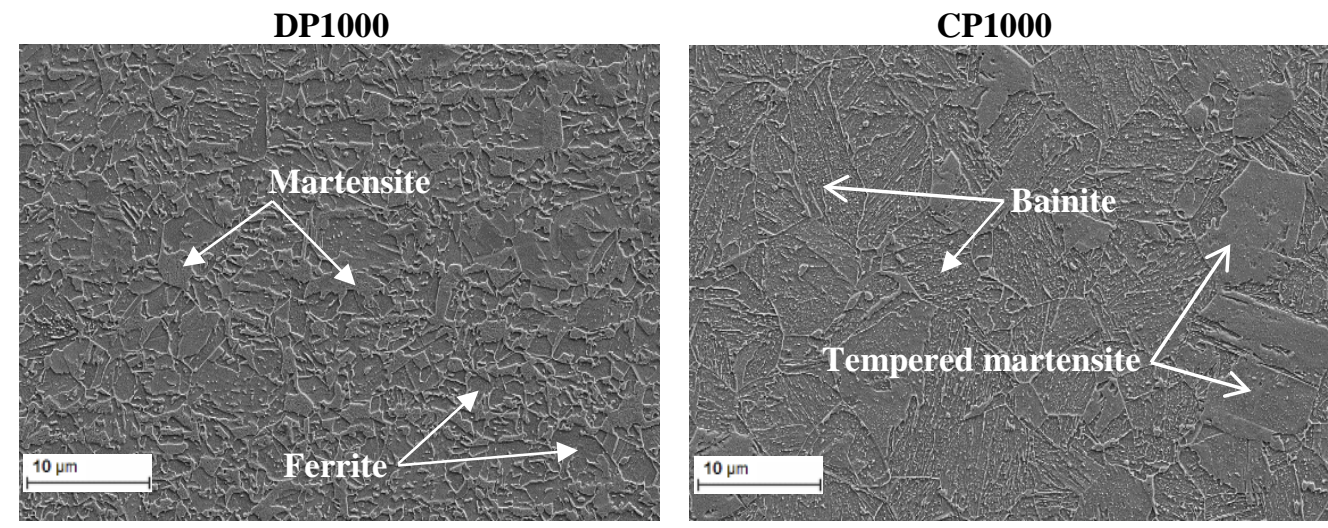

Figure 3. Microstructures of DP1000 (left) and CP1000 (right). 


\section{Experimental results}

In order to characterize the fracture resistance of the studied steel sheets and rationalize the cold forming behaviour, different mechanical tests were performed.

\subsection{Tensile tests}

Conventional uniaxial tensile tests according EN-ISO 6892 were performed at transverse orientation respect to the rolling direction with an initial gauge length of $80 \mathrm{~mm}$. 3 specimens per material were tested. Engineering stress-strain curves obtained from tensile tests are shown in figure $4 \mathrm{a}$ and tensile parameters are summarized in table 2 .

Both steel grades present identical maximum strength. DP1000 shows low yield strength, a great strain hardening and large elongation. On the other hand, CP1000 exhibits higher yield strength, but lower work hardening rate and elongation. Such mechanical properties are controlled by their complex microstructures. In DP steels, the combination of a soft ferritic matrix and hard martensitic phases provides good ductility and attain high tensile strength. The great work hardening rate is caused by the limited deformation of ferrite due to the presence of hard martensite islands, which means higher rate of dislocations accumulation. The homogeneous multiphase microstructure of CP steels leads to attain higher yield strength, but the elongation obtained in this kind of steels is smaller than in DP.

Table 2. Tensile parameters at transverse direction: yield strength $\left(\sigma_{\mathrm{ys}}\right)$, Ultimate Tensile Strength ( $\sigma_{\mathrm{UTS}}$ ), elongation at fracture and work hardening coefficient (n).

\begin{tabular}{|c|c|c|c|c|c|c|}
\hline & $\mathbf{t}[\mathbf{m m}]$ & $\sigma_{\mathrm{ys}}[\mathrm{MPa}]$ & $\sigma$ uTs [MPa] & Elongation at fracture [\%] & n $2-4 \%$ & $\begin{array}{c}\text { Area under } \\
\text { tensile curve } \\
\text { [MPa*\%] }\end{array}$ \\
\hline DP1000 & 1.2 & 697 & 1018 & 11.99 & 0.18 & 11286 \\
\hline CP1000 & 1.2 & 904 & 1022 & 7.97 & 0.07 & 7677 \\
\hline
\end{tabular}

\subsection{Formability tests}

Formability of the two steel grades has been assessed through Nakajima stretching tests. They were performed according to ISO 12004 to obtain the Forming Limit Curves (FLC). Grease, Teflon and polyurethane disks were inserted between the punch and the sample to minimize the friction between the parts. Six different geometries were used to obtain the different strain paths and determine the FLCs (figure $4 \mathrm{~b}$ ). 3 specimens for each geometry were evaluated. A blank holder force of $600 \mathrm{kN}$ was applied and the punch speed was set to $90 \mathrm{~mm} / \mathrm{min}$.

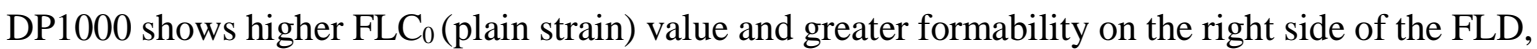
corresponding to biaxial strain modes. In the left side of FLD (uniaxial strain paths) CP1000 shows slightly better behaviour. However, the information corresponding to negative minor strains is limited, since the level of minor strain reached with the tested geometries is low, especially for CP1000 (minimum minor strain: 0.03).

\subsection{Stretch flangeability tests}

HET were performed according to ISO 16630 [7] to evaluate the stretch flangeability of the investigated AHSS. 6 specimens per each material were evaluated. The tests were conducted with a punch speed of $1 \mathrm{~mm} / \mathrm{s}$ and a clamping force of $600 \mathrm{kN}$ was applied to avoid any material draw-in from the clamping area during the test. The initial hole diameter was $10 \mathrm{~mm}$ and the cutting tolerance was set to $12 \%$.

The value obtained from HET is the HER, which represents the maximum diametric expansion that a circular punched hole can reach when a conical tool is forced into it until a crack in the hole edge extends through the full sheet thickness. 
HER values are plotted in figure 4c. DP1000 shows HER values from $12 \%$ to $22 \%$ and CP1000 from $47 \%$ to $84 \%$. Such high variability has been previously reported by other authors $[24,25]$.

CP1000 shows much larger hole expandability than DP1000. The lower stretch flangeability of DP steels is explained by the hardness difference between the ferrite and martensite phases. On the other hand, the smaller difference in properties between phases and lower internal stresses in CP grades lead to improved hole expansion behaviour [2, 9].

\subsection{Essential Work of Fracture tests}

The fracture toughness of the studied AHSS grades was evaluated by means of the EWF tests. EWF tests are performed following the procedure stablished in the European Structural Integrity Society (ESIS) protocol [26]. Rectangular Double Edge Notched Tensile (DENT) specimens of 90 x $40 \mathrm{~mm}$ were extracted from the cold formed components at $0^{\circ}$ respect to the rolling direction. A total of 10 specimens per material were tested with 4 different ligament lengths ranging from 7 to $14 \mathrm{~mm}$. 2 specimens were evaluated for each intermediate ligament (9 and $11 \mathrm{~mm})$, whereas for the extreme ligament lengths ( 7 and $14 \mathrm{~mm}$ ) 3 specimens per ligament were tested.

The tests were performed at a constant cross-head speed of $1 \mathrm{~mm} / \mathrm{min}$ and a gauge length of $25 \mathrm{~mm}$ was used. To avoid the effect of notch root radius in the fracture toughness evaluation, fatigue pre-cracks were introduced on the notch root. It must be noted that $w_{e}$ is not fully a material intrinsic property but it is influenced by the sheet thickness, since plane stress fracture toughness depends on the volume available to deform plastically at the front of crack tip. Hence, $w_{e}$ is a fracture toughness value for the evaluated sheet thickness.

Figure 4d shows the EWF results obtained for DP1000 and CP1000 steel grades. It is observed that $\mathrm{CP}$ grade exhibits much greater fracture toughness than DP. Remarkable differences in toughness between CP and DP steel grades were reported previously by other authors [3, 10].

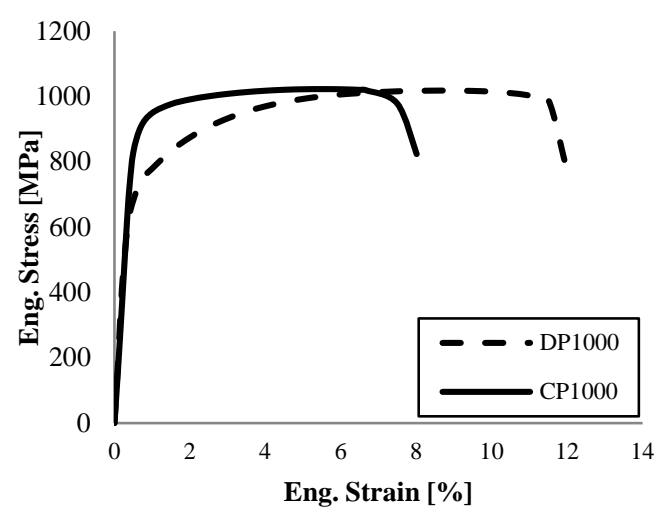

a)

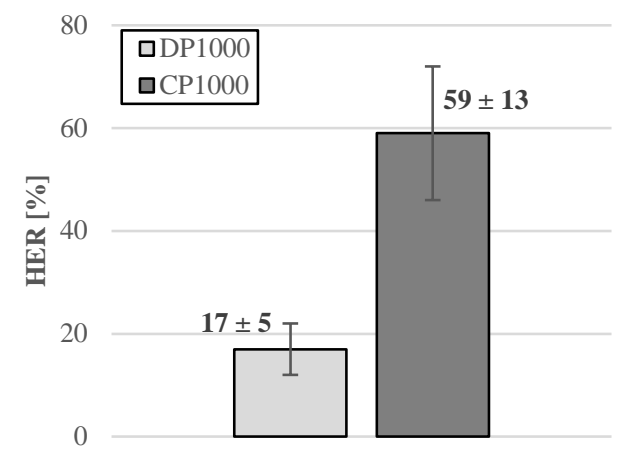

c)

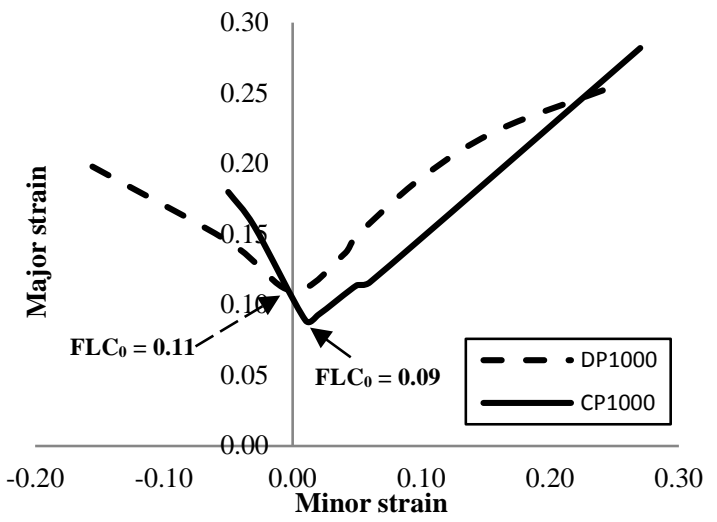

b)

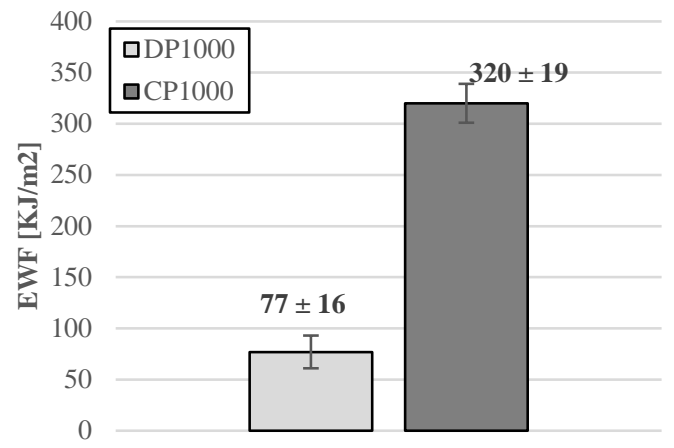

d)

Figure 4. Experimental results obtained with the investigated CP and DP grades. a) Tensile curves, b) FLCs, c) HER values and d) EWF values. 
36th IDDRG Conference - Materials Modelling and Testing for Sheet Metal Forming

IOP Publishing

IOP Conf. Series: Journal of Physics: Conf. Series 896 (2017) 012102

doi:10.1088/1742-6596/896/1/012102

\section{Discussion}

DP1000 shows much greater elongation than CP1000 in tensile tests, what would indicate higher ductility of the DP grade, and much higher n-value, generally associated to greater formability. However, DP1000 showed extensive edge cracking compared to CP1000. It must be noted that tensile tests evaluate only global damage. The fracture elongation obtained is an average strain along a gauge length and such strain value totally underestimates the local ductility potential of the material. Hisker et al. found that the microstructure of DP-steels is more sensitive to localized damage but it is compensated by the great work-hardening [28]. Thus, DP steels present great tensile properties but poor stretchflangeability. However, the homogeneous microstructure of CP-steels is less sensitive to localized damage but has limited capacity for work-hardening, which leads to lower elongation in tensile tests but higher edge stretchability [28].

Fracture energy extracted from tensile test is also not suitable to describe edge cracking. Classical toughness definitions are based on the energy obtained from the area under the engineering curves and, usually, higher energy is associated with higher toughness (figure 4a, table 2). DP1000 shows higher fracture energy than CP1000. Hence, such energy values do not describe edge cracking.

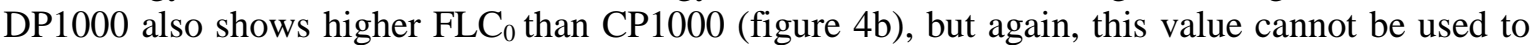
understand edge cracking. FLD is suitable to evaluate the formability of AHSS when general deformation modes are present, but for shearing or edge stretching a poor correlation is obtained and FLC fails to predict the fracture [6]. The deformation mode for edge stretching is uniaxial tension. The fracture of the specimens in FLD tests at uniaxial tension is preceded by localized necking in the bulk material. Thus, the fracture strain determined overestimates edge cracking, which occurs before considerable necking at a much lower strain level $[5,24]$.The different edge crack behavior showed by DP1000 and CP1000 cannot be explained by means of conventional approaches, i.e. fracture elongation from tensile tests or FLC.

HET has shown to be suitable to estimate the stretch flangeability of AHSS [5, 24 and 27]. HER values obtained from the investigated steels (figure 4c) highlight the greater edge cracking resistance of CP steel grade against DP steel. The poor stretch flangeability showed by the DP justify the appearance of multiple edge cracks, observed in the cold formed component. However, the big scattering observed in the measurements can lead to question the objectivity of the method to characterize edge cracking sensitivity. Such scatter is attributed to the high number of variables during the test: amount of damage introduced during punching, method of crack detection, etc.

Fracture toughness measured in the frame of EPFM, through the EWF tests, can also be used as a material property to understand edge cracking. The EWF measurements carried out show that the fracture toughness of the CP1000 steel grade is much greater than the DP1000 steel ones (figure 4d) and it is found that higher EWF is related to greater HER values (figure 4c). Hence, the EWF is able to rationalize the poor edge cracking resistance of DP1000 and justify the appearance of multiple cracks at the edges of the cold formed component. This is in agreement with previous works that showed a very good correlation between HER and EWF $[3,10]$. Such authors proposed EWF as an alternative method to evaluate the stretch-flangeability of AHSS. The results obtained in the present work are in good agreement with these investigations and support such proposal.

As a matter of comparison, the values of EWF and HET obtained here are plotted together with results from reference [10], in figure 5. It can be observed that results fit quite well in the almost linear correlation, and allows pointing out EWF as a material property and a reliable experimental parameter to evaluate stretch-flangeability of CP and DP steels and predict edge crack sensitivity. 


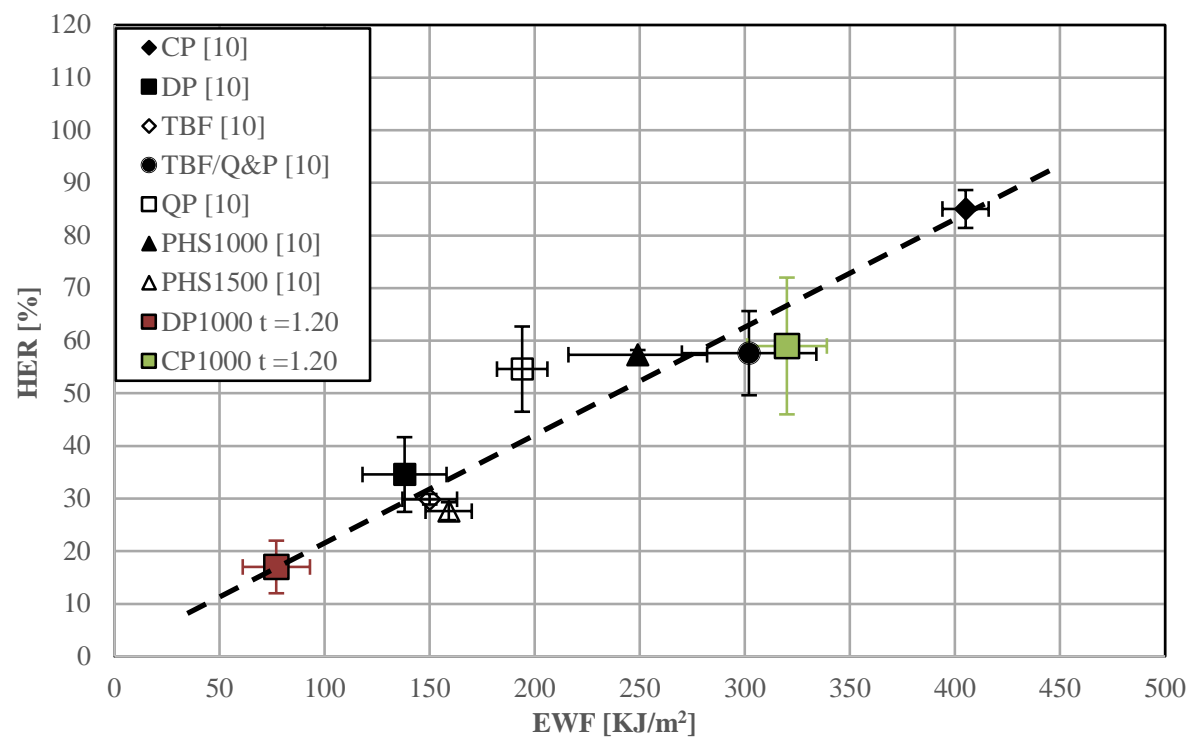

Figure 5. EWF against HER. CP and DP steel grades investigated in this work together with other AHSS grades reported in reference 10 .

\section{Conclusions}

From the investigations carried out in this work with a serial produced AHSS automotive component and with the results of different mechanical tests, the following conclusions can be drawn:

- Conventional approaches, such as FLD or tensile tests are not capable to predict edge cracking sensitivity of DP and CP steels.

- It is shown that EWF methodology is a reliable tool to evaluate the fracture toughness of CP and DP steel grades and can properly rationalize edge cracking related problems.

- EWF is proposed as a parameter to select AHSS grades with improved stretch flangeability and avoid unexpected edge fractures during cold forming processes.

\section{Acknowledgments}

The research leading to these results has been partially funded by the European Commission, Research Fund for Coal and Steel, under grant agreement RFSR-CT-2014-00015 (Tough-Sheet).

\section{References}

[1] Steel Market Development Institute 20162016 Steel Industry Technology Roadmap for Automotive. www.autosteel.org

[2] Wu X, Bahmanpour H and Schmid K 2012 Characterization of mechanically sheared edges of dual phase steels J. Mat. Proc. Tech. 212 1209-1224

[3] Gutiérrez D, Pérez LL, Lara A, Casellas D and Prado J M 2013 The influence of fracture toughness in stretch-flangeability in advanced high strength steels sheets Proceedings of the IDDRG 2013 (Zurich, Switzerland, June 02-05)

[4] Takahashi Y, Kawano O and Tanaka Y 2009 Fracture Mechanical Study on Edge Flange-ability of High Tensile-strength Steel Sheets MS\&T 2009: Proceedings from the Materials Science \& Technology Conference (October 25-29, 2009, Pittsburgh, Pennsylvania) pp 1317-1328.

[5] Larour P, Pauli H, Freudenthaler J and Grünsteidl A 2011 Alternative stretch flangeability characterisation methods for AHSS steel grades Proceedings of the IDDRG2011 (Bilbao, Spain, June 05-08)

[6] Chen X, Sun J and Zhu X 2012 Simulation Technique for Pre-forming of AHSS Edge Stretching $12^{\text {th }}$ International LS-DYNA ${ }^{\circledR}$ Users Conference (Michigan,USA,June 03-05)

[7] ISO/TS16630. Metallic materials - Method of hole expanding test, 2003 
[8] Takahashi Y, Kawano O, Ushioda K and Aihara S 2012 Fracture Mechanical Study on Stretch Flange-Ability of Hot-Rolled High Tensile Strength Steel Sheets Proceedings of Asia Steel International Conference 2012

[9] Fonstein N, Jun HJ, Huang G, Sriram S and Yan B 2011 Effect of Bainite on Mechanical Properties of Multiphase Ferrite-Bainite-Martensite Steels Proceedings from the Materials Science \& Technology Conference (October 16-20, 2011, Columbus, Ohio)

[10] Casellas D, Lara A, Frómeta D, Gutiérrez D, Molas S, Pérez LL, Rehrl J and Suppan C 2017 Fracture Toughness to Understand Stretch-Flangeability and Edge Cracking Resistance in AHSS Metall and Mat Trans A 48 86-94

[11] Yoon J I, Jung J , Joo S H, Song T J, Chin K G, Seo M H, Kim S J, Lee S and Kim H S 2016 Correlation between fracture toughness and stretch-flangeability of advanced high strength steels Matter.Lett. 180 322-326

[12] ASTM E1820. Standard Test Method for Measurement of Fracture Toughness, 2013.

[13] Cotterell B and Reddel JK 1977 The essential work of plane stress ductile fracture Int.J.Fracture 13 267-277

[14] Mai YW and Cotterel B 1986 On the essential work of ductile fracture in polymers Int.J.Fracture 32 105-125

[15] Wu J and Mai YW 1996 The Essential Fracture Work Concept for Toughness Measurement of Ductile Polymers Polym.Eng. Sci 36 2275-2288

[16] Martínez AB, Gámez-Pérez J, Sanchez-Soto M, Velasco JI, santana O.O, and Maspoch MLL 2009 The Essential Work of Fracture method- Analyzing the Post-yielding Fracture Mechanics of polymers Eng. Fail. Anal. 16 2604-2617

[17] Marchal Y and Delannay F 1998 Comparison of methods for fracture toughness testing of thin low carbon steel plates. Mater Sci Tech Ser 14 1163-1168

[18] Cotterell B, Pardoen T and Atkins AG 2005 Measuring toughness and the cohesive stressdisplacement relationship by the essential work of fracture concept. Eng. Fract. Mech. 72 827848

[19] Marchal Y and Delannay F 1996 Influence of test parameters on the measurement of the essential work of fracture of zinc sheets. Int Fract J $\mathbf{8 0} 295-310$

[20] Pardoen T, Marchal Y and Delannay F 1999 Thickness dependence of cracking resistance in thin aluminium plates J.Mech.Phys.Solids 47 2093-2123

[21] Llobet A, Casellas D, Riera MD and Prado JM 2008 Fracture toughness characterization of Advanced high strength Steels by means of the Essential Work of Fracture Proceedings from International Conference on New Developments in Advanced High-Strength Sheet Steels (Orlando,USA,June 15-18)

[22] Muñoz R, Lara A and Casellas D 2011 Fracture toughness characterization of advanced high strength steels Proceedings of the IDDRG2011 (Bilbao, Spain, June 05-08)

[23] Lacroix G, Pardoen T and Jacques PJ 2008 The fracture toughness of TRIP-assisted multiphase steels Acta Mater. 56 3900-3913

[24] Larour P, Freudenthaler J, Grünsteidl A and Wang K 2014 Evaluation of alternative stretch flangeability testing methods to ISO 16630 standard Proceedings of the IDDRG2014 (Paris, France, June 01-04)

[25] Larour P, Freudenthaler J, Lackner J, Leomann F and Schestak G 2016 Experimental artefacts on ISO 16630 hole expansion ratio Proceedings of the IDDRG2016 (Linz, Austria, June 12-15)

[26] Clutton E, Moore DR 2003 ESIS EWF Protocol: Essential work of fracture and cohesive zone fracture toughness.

[27] Shi M and Chen X 2007 Prediction of Stretch Flangeability Limits of Advanced High Strength Steels using the Hole Expansion Test SAE Technical Paper 2007-01-1693

[28] Hisker F, Thiessen R and Heller T 2012 Influence of Microstructure on Damage in Advanced High Strength Steels Mater. Sci. Forum 706-79 925-930 